\title{
A Study of Chloride Diffusion Properties of Concrete at Early Age
}

W.D. Yeih

Department of Harbor and River Engineering National Taiwan Ocean University Keelung 20224, Taiwan, Republic of China

R. Huang

Department of Harbor and River Engineering National Taiwan Ocean University Keelung 20224, Taiwan, Republic of China

J.J. Chang

Department of Harbor and River Engineering National Taiwan Ocean University Keelung 20224, Taiwan, Republic of China

Follow this and additional works at: https://jmstt.ntou.edu.tw/journal

Part of the Civil and Environmental Engineering Commons

\section{Recommended Citation}

Yeih, W.D.; Huang, R.; and Chang, J.J. (1994) "A Study of Chloride Diffusion Properties of Concrete at Early Age," Journal of Marine Science and Technology. Vol. 2: Iss. 1, Article 8.

DOI: $10.51400 / 2709-6998.2489$

Available at: https://jmstt.ntou.edu.tw/journal/vol2/iss1/8

This Research Article is brought to you for free and open access by Journal of Marine Science and Technology. It has been accepted for inclusion in Journal of Marine Science and Technology by an authorized editor of Journal of Marine Science and Technology. 


\section{A Study of Chloride Diffusion Properties of Concrete at Early Age}

Acknowledgements

The authors wish to express sincere thanks to finacial support of this study by Taiwan Area National Expressway Engineering Bureau (TANEEB). 


\title{
A STUDY OF CHLORIDE DIFFUSION PROPERTIES OF CONCRETE AT EARLY AGE
}

\author{
W.D. Yeih, R. Huang and J.J. Chang \\ Department of Harbor and River Engineering \\ National Taiwan Ocean University \\ Keelung 20224, Taiwan, Republic of China
}

Key words: concrete, mortar, chloride diffusion.

\begin{abstract}
Existence of chloride ions in concrete may accelerate reinforcement corrosion. Chloride ions can penetrate into the concrete by the diffusion process even if no major cracks exist. It is well known that properties of concrete will change with time since the hydration reaction continues for a long time, which implies that the diffusion coefficient of concrete is a timedependent function. In this research, the diffusion behavior is focused on early-age mortar and concrete. It is shown that the diffusion coefficient changes dramatically at early age; and the control of interface property is significantly important to chloride diffusion. The effect by adding silica fume in concrete and mortar is also examined.
\end{abstract}

\section{INTRODUCTION}

Corrosion problem of $\mathrm{RC}$ structure is very serious in marine environment since penetration of chloride ions can locally destroy the passive oxide layer of reinforcements. Various critical chloride ion contents are reported by different authors and found in Funahashi's paper [1]. Even though different viewpoints are proposed in current date, they all agree that the chloride ion is a key factor affecting corrosion of rebars in marine environment. The penetration of chloride ions can be categorized into two main domains according to the driving force. One is due to pressure difference where Darcy's law is concerned, a typical example is the penetration of chloride ions in concrete in the submerged zone. The other is due to the difference of concentration where diffusion effect is concerned [2]. Usually the penetration mechanism of chloride ions dominated by pressure difference is not significant in most cases. Two types of chloride ions in concrete can be distinguished, one is free chloride ions which can be transferred in concrete freely and another type of chloride ions can react with $\mathrm{C}_{3} \mathrm{~A}$ and $\mathrm{C}-\mathrm{S}-\mathrm{H}$ paste to yield friedel salt, i.e. $\mathrm{C}_{3} \mathrm{~A} \cdot \mathrm{CaCl}_{2} \cdot 10 \mathrm{H}_{2} \mathrm{O}$ or physically absorded by $\mathrm{C}-\mathrm{S}-\mathrm{H}$ paste so that they would not affect reinforcement corrosion.

Several conditions will affect the diffusivity of chloride ions. Tikalsky et al [3] and Maslehuddin et al [4] found that adding fly ash or silica fume can reduce the pore size of concrete, thus decrease the diffusivity of chloride ions. Page, Short and Tarras [5] found that the diffusivity would increase while temperature increased. They also found that the diffusion rate of chloride ions became 4 to 6 times larger while w/c ratio was increased from 0.4 to 0.6. Gjørv and Vennesland [6] reported that while penetration depth is greater than $20 \mathrm{~mm}$, not much difference of chloride ions' content in mortar specimen no matter what water - cement ratio was. Clear and Hay [7] published a report to describe the effect of cement type on the diffusivity of chloride ions, they evidently found that the type of cement can cause different diffusivity, which is due to different $\mathrm{C}_{3} \mathrm{~A}$ content in cement. Page, Short and Holden [8] reported that pulverized fly ash concrete and blast furnace slag concrete can reduce diffusivity and the use of type II cement has higher diffusivity comparing with $\mathrm{OPC}$.

Diffusion equation is usually used to describe mass transfer of chloride ions in concrete. Solutions for submerged zone can be expressed by error function [9], and solutions for splash zone and atmospheric zone can be found in reference [2]. A basic assumption for abovementioned solutions is that the diffusion coefficient is not time-dependent, i.e. concrete is considered as a steadystate material. However, concrete properties change with time especially at early age. Based on 1,200-day data, 
Magnet and Gurusamy [10] [11] reported that the diffusion coefficient of chloride ions can be expressed as $D(t)=$ $[2.81+7 \cdot \exp (-0.005 t)] \times 10^{-8}\left(\mathrm{~cm}^{2} / \mathrm{sec}\right)$ for ordinary portland cement concrete and $D(t)=(10.54-0.0168 t-1.181 \times$ $\left.10^{-5} t^{2}+2.148 \times 10^{-8} t^{3}\right) \times 10^{-8}\left(\mathrm{~cm}^{2} / \mathrm{sec}\right)$ for fly ash concrete. When the property is a function of time, by assigning $D(t)$ $=D_{0} f(t)$ and employing a transformation $T=\int_{0}^{t} f(t) d t$ the diffusion equation $\frac{\partial C}{\partial t}=D(t) \frac{\partial^{2} C}{\partial x^{2}}$ can be transformed into a standard type diffusion equation, $\frac{\partial C}{\partial T}=D_{0} \frac{\partial^{2} C}{\partial x^{2}}$.

In this paper, the diffusion coefficients of chloride ions in mortar and concrete specimen at early age were studied and effect of adding silica fume on chloride diffusion was also examined. Diffusion coefficients for mortar and concrete were compared and analyzed. Best-fit curves were developped to describe diffusion coefficients and predict diffusion behavior of chloride ions.

\section{EXPERIMENTAL APPARATUS AND PROCEDURES}

\section{Specimens}

Both mortar and concrete specimens were prepared. Three different $\mathrm{w} / \mathrm{c}$ ratios were used for mortar specimens and one w/c ratio was used for concrete. Details of mix design are listed as the following table.

In the mix design, w/c ratio is calculated by water divided by cementitious material. Compressive strength specimen were $\$ 100 \mathrm{~mm} \times 200 \mathrm{~mm}$ cylinders for concrete and $50 \mathrm{~mm} \times 50 \mathrm{~mm} \times 50 \mathrm{~mm}$ cubes for mortar.

\section{Diffusion Cell}

Diffusion cell was designed as a $100 \mathrm{~mm} \times 200 \mathrm{~mm} \times$ $120 \mathrm{~mm}$ rectangular container, a $4 \mathrm{~mm}$-thick plate with two
$25 \mathrm{~mm} \times 25 \mathrm{~mm}$ square holes was placed between two cells. The detail of diffusion cell is illustrated in Figure 1. After 7 days or 28 days curing, concrete or mortar were cut into a $25 \mathrm{~mm} \times 25 \mathrm{~mm}$ square thin plate with a thickness of $4 \mathrm{~mm}$. After placing specimens, four sides of the plate were sealed with silicon to prevent leakage.

\section{Chloride measurement}

Several testing methods are available for chloride measurement. Traditionally, the chemical titration method is the most popular method employed by the researchers. In this study, chloride contents were monitored by chloride-selective eletrodes. One of the diffusion cell was filled with $3.5 \% \mathrm{NaCl}$ solution and the other one was filled with distilled water. As diffusion last, chloride contents was continuously monitored.

\section{RESULTS AND DISCUSSION}

\section{Diffusion coefficient and compressive strength}

Mortar specimens can be divided into two groups according to the age of curing: 7-day curing and 28-day curing. After curing, specimens were cut into thin plates to place into diffusion cells and chloride contents were monitored. Changes of diffusion coefficients with time are illustrated in Figure 2 to Figure 3. Concrete specimens were water-cured for 7 days and similar procedures were repeated as for mortar specimens. Results are illustrated in Figure 4. The compressive strengths for mortar and concrete specimens are listed in Table 2.

\section{Effect of w/c ratio on diffusion coefficient}

As we know, w/c ratio is a key factor to control the property of concrete. General speaking, concrete is more

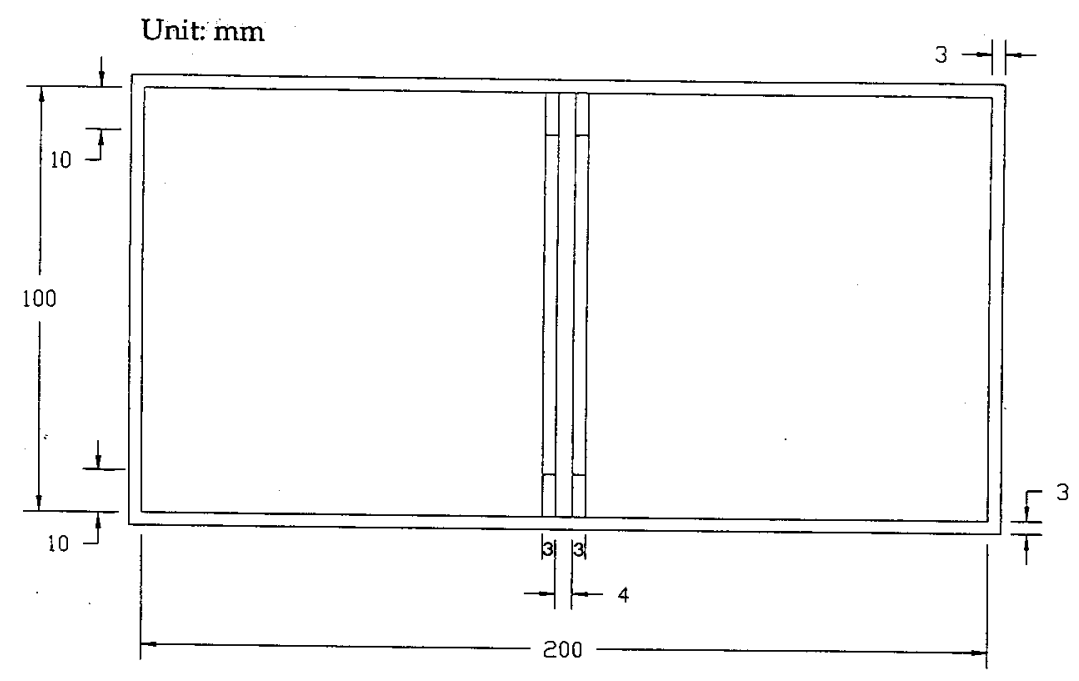

Fig. 1. Diffusion cell setup.

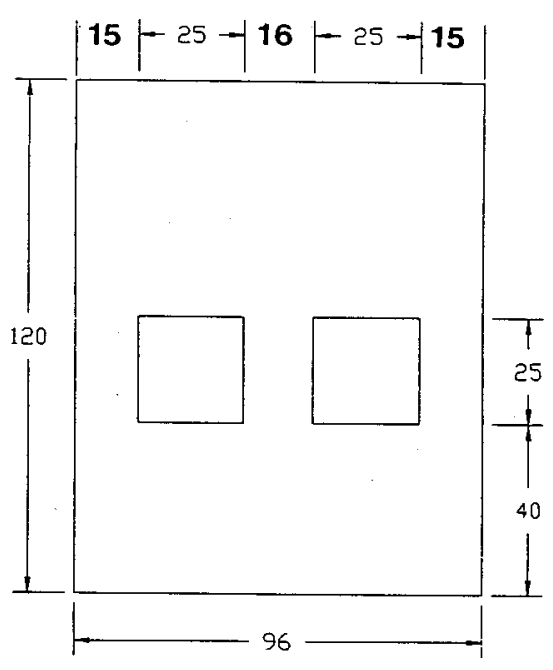


Table 1. Mix design for OPC and aortar specimen

\begin{tabular}{|c|c|c|c|c|c|c|c|}
\hline & label no. & $\mathrm{w} / \mathrm{c}$ & cement & water & aggregate & sand & silica fume \\
\hline \multirow{5}{*}{ mortar } & M5 & 0.5 & 536 & 268 & 0 & 1475 & 0 \\
\hline & M6 & \multirow{3}{*}{0.6} & 500 & 300 & 0 & 1375 & 0 \\
\hline & M6S1 & & 463 & 300 & 0 & 1375 & 38 \\
\hline & M6S2 & & 425 & 300 & 0 & 1375 & 76 \\
\hline & M7 & 0.7 & 480 & 36 & 0 & 1320 & 0 \\
\hline \multirow{3}{*}{ OPC } & C6 & \multirow{3}{*}{0.6} & 318 & 191 & 1193 & 636 & 0 \\
\hline & C6S1 & & 294 & 191 & 1193 & 636 & 24 \\
\hline & C6S2 & & 270 & 191 & 1193 & 636 & 48 \\
\hline
\end{tabular}

Unit: $\mathrm{Kg} / \mathrm{m}^{3}$

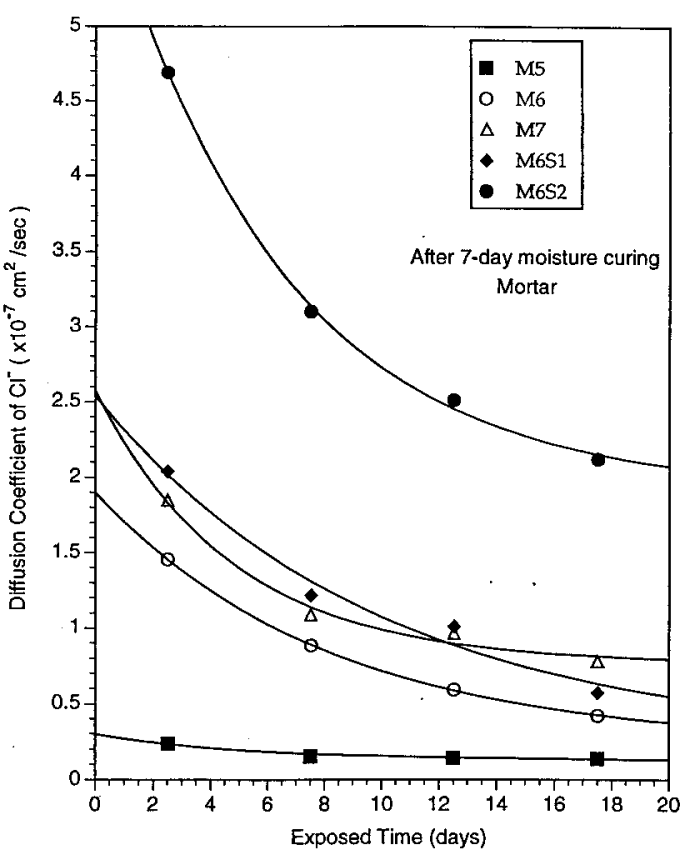

Fig. 2. Diffusion coefficients vs. exposed time for 7-day curing mortar specimens.

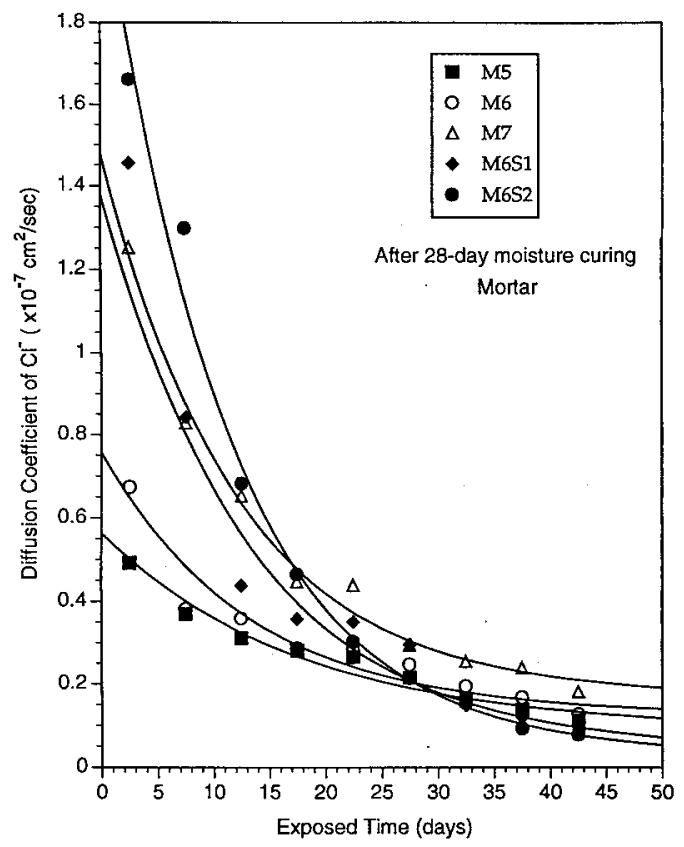

Fig. 3. Diffusion coefficients vs. exposed time for 28-day curing mortar specimens.

Table 2. Compressive Strength (MPa)

\begin{tabular}{|c|c|c|c|c|c|c|c|c|}
\hline daysVabel & M5 & M6 & M6S1 & M6S2 & M7 & C6 & C6S1 & C6S2 \\
\hline 3 & --- & --- & --- & --- & --- & 8.7 & 10.8 & 12.9 \\
\hline 7 & 26.9 & 20.4 & 22.9 & 19.2 & 13.5 & 10.2 & 11.2 & 16.7 \\
\hline 28 & 39.8 & 31.2 & 36.7 & 28.2 & 27.1 & 14.7 & 19.3 & 24.7 \\
& $(0.472)^{*}$ & $(0.674)$ & $(1.456)$ & $(1.661)$ & $(1.253)$ & $(0.575)$ & $(0.575)$ & $(0.444)$ \\
\hline 60 & $\begin{array}{c}40.5 \\
(0.164)\end{array}$ & $\begin{array}{c}33.3 \\
(0.195)\end{array}$ & $\begin{array}{c}42.1 \\
(0.149)\end{array}$ & $\begin{array}{c}42.8 \\
(0.154)\end{array}$ & $\begin{array}{c}31.1 \\
(0.256)\end{array}$ &.--- & $-\cdots--$ & ---- \\
\hline
\end{tabular}

*:value ()$\times 10^{-7}\left(\mathrm{~cm}^{2} / \mathrm{sec}\right)$ is diffusion coefficient. 


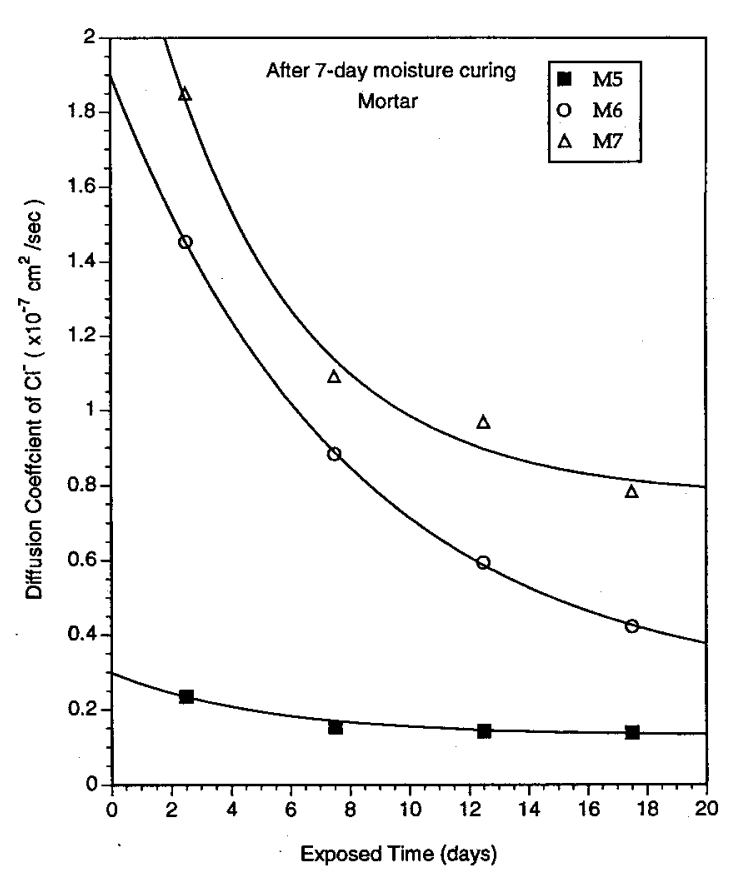

Fig. 4. Diffusion coefficients vs. exposed time for 7-day curing concrete specimens.

dense if $w / c$ ratio is lower. This imply the diffusion coefficient will increase as w/c ratio increases. Gjørv and Vennesland [6] reported that the diffusion coefficient did not change significantly with w/c ratio after longterm exposure. Figures 5 and 6 show the diffusion coefficient of 7-day and 28-day curing mortar specimens with respect to exposed time respectively. From this study, it can be found that the diffusion coefficient is dependent on w/c ratio for specimens at early age. As exposed time increases, the difference between specimens with various $w / c$ ratios decreases.

\section{Effect of silica fume on compressive strength and diffu- sion coefficient}

\section{Mortar}

Silica fume is one of the pozzolan materials which can yield extra C-S-H paste through the pozzolan reaction. Figure 7 shows that adding silica fume as partial substitution of cement has higher diffusion coefficients than the control group before exposed 28 days. However, after 28 days silica-fume mortar has lower diffusion coefficient. The reasons and several mechanisms are listed as below:

1. When silica fume is used as partial substitution for cement, the amount of $C_{3} A$ will decrease (under same w/c ratio). $C_{3} A$ reacts with chloride ions so that free chloride ions decrease, and the diffusion coefficient will decrease.

2. Before pozzolan reaction happens, silica fume can be considered as fine aggregate. It can fill the micr-

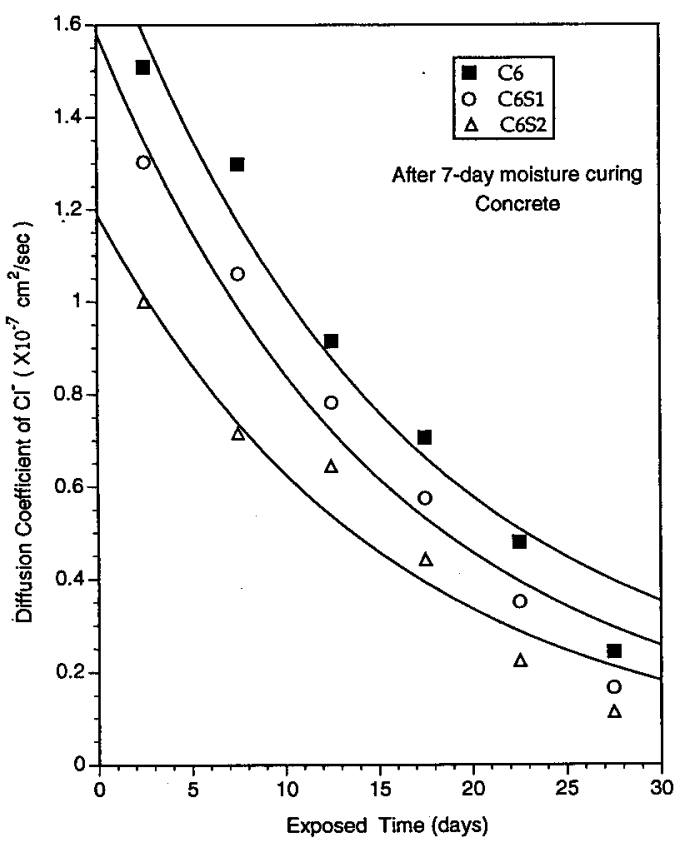

Fig. 5. Effect of w/c ratio on the chloride diffusion for 7-day curing mortar specimens.

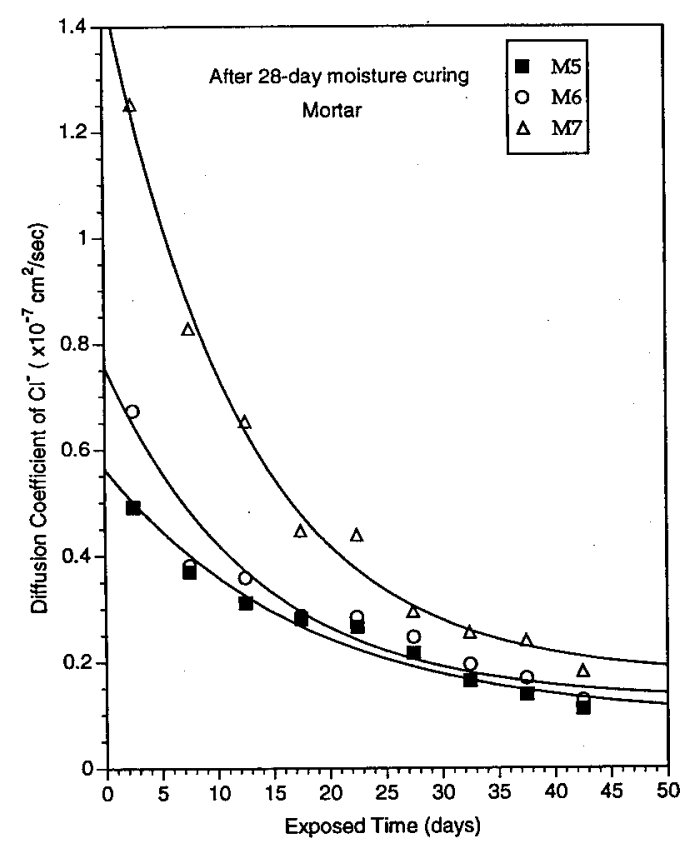

Fig. 6. Effect of w/c ratio on the chloride diffusion for 28-day curing mortar specimens.

opores between C-S-H paste to reduce diffusion rate, however it is not benefit for compressive strength because of increasing weak interface areas.

3. At the early age, silica fume substitution will reduce the hydration reaction rate such that the compressive strength becomes lower and diffusion coefficient is higher. As pozzolan reaction continues, the compressive strength will increase if appropriate substitution 


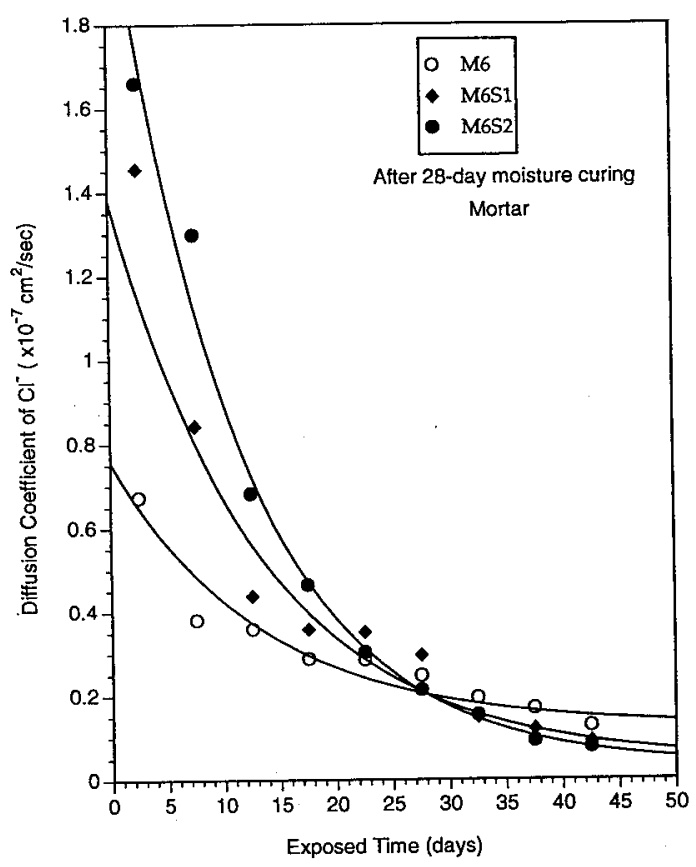

Fig. 7. Effect of silica fume on the chloride diffusion behavior in mortar.

is applied. At the same time, diffusion coefficient will decrease.

At the early age, even silica fume can fill micropores, the diffusion behavior is still controlled by low hydration rate and $\mathrm{C}_{3} \mathrm{~A}$ effect. Thus, no matter what substitution amount, a higher diffusivity is shown compared with control specimens. From Table 2, it can be found the compressive strengths at age of 7 days and 28 days have M6S1 $>$ M6 $>$ M6S2 order. This shows pozzolan effect already develops before 28 days, however $15 \%$ substitution is too large so that part of silica fume particles still remain as fine aggregate. It is also observed that $7.5 \%$ silica fume substituition group has higher compressive strength than control group and the diffusion coefficient is higher. The reason was previously explained. At the age of 60 days (exposed for 32 days), diffusion coefficient of control group became highest and $15 \%$ silica fume substitution group showed lowest diffusion coefficient. Also from Table 2,15\% silica fume substitution group has the highest compressive strength and control group has the lowest strength at age of 60 days. It can be concluded that pozzolan effect may be fulfilled by that time and the properties of concrete is dominated mainly by pozzolan effect.

\section{Concrete}

The coarse aggregates and the transition zone around coarse aggregates exist in concrete. Therefore, two new mechanisms should be considered: penetration. While silica fume still remain as fine particles, micropores in transition zone can be filled so that diffusion coefficient will be reduced. Silica fume will increase the compressive strength since it improves the property of transition zone;

2* Coarse aggregates are more dense than $\mathrm{C}-\mathrm{S}-\mathrm{H}$ paste. Penetration of chloride ions mainly pass through transition zone and mortar. Thus, concrete has lower effective diffusion area compared with mortar.

Item $1^{*}$ and $2 *$ are much more important than items 1 to 4 in concrete. From Table 2 , it can be found adding silica fume improves the compressive strength. Also from Figure 4, 15\% silica fume substitution group has the lowest diffusion coefficient and control group has the highest value. It can be concluded that the compressive strength and diffusivity is dominated by transition zone property.

\section{Best-fit curves and prediction of penetration depth}

Diffusion rate of chloride ions depends on material property. The properties of concrete and mortar change with time since hydration reaction continues. In this study, it is found the diffusion coefficient changes rapidly at early age and its tendency slows down as hydration reaction rate becomes lower. From experimental data, best-fitting curves can be found. Theoretical speaking, best-fitting curve can be chosen in many ways. However, experience and physical judgement are needed to determine which curve is suitable. According to test data, the diffusion coefficient decreases with time, and finally reaches a stable value. In addition, the time derivative of diffusion coefficient is negative. In this study, the model of best-fitting curves can be chosen as $D(t ; a, b, c)=a+b$ $\exp (-c t)$. The equations of best-fit curves in this study are tabulated in Table 3.

Chloride ion penetrations can be caculated using best-fit curves. The prediction of chloride ion concentration vs. penetration depth is shown in Figure 8 for concrete in the submerged zone.

\section{CONCLUSIONS}

In this study, the diffusion behaviors of chloride ions in mortar and concrete at early age are evaluated. It is found that the diffusion coefficients change rapidly with time at early age and the change rate decreases with time. Adding silica fume in mortar increases the diffusion coefficient at early age. However, diffusion coefficients of silica fume mortar areless than those of ordinary portland cement mortar after pozzolanic reaction fulfills. According to this study, the use of silica fume in concrete decreases the diffusion coefficient and the more silica fume results in the less diffusion coefficient. The difference of diffusion coefficient between mortar and concrete mainly can be explained by the transition zone around 
Table 3. Coefficients of best-fit curves

\begin{tabular}{|l|c|l|}
\hline Label No & Curring age & Best-fit curve (Uit: $\left.\mathrm{cm}^{2} / \mathrm{sec}\right)$ \\
\hline M5 & 7 days & $D\left(t^{*}\right)=2.38 \times 10^{-8}+1.66 \times 10^{-7} \exp \left(-1.25 \times 10^{-1} t\right)$ \\
\hline M6 & 7 days & $D\left(t^{*}\right)=1.29 \times 10^{-8}+0.17 \times 10^{-7} \exp \left(-1.921 \times 10^{-1} t\right)$ \\
\hline M6S1 & 7 days & $D(t)=2.59 \times 10^{-8}+2.28 \times 10^{-7} \exp \left(-1.035 \times 10^{-1} t\right)$ \\
\hline M6S2 & 7 days & $D(t)=1.91 \times 10^{-8}+4.17 \times 10^{-7} \exp \left(-1.642 \times 10^{-1} t\right)$ \\
\hline M7 & 7 days & $D(t)=7.67 \times 10^{-8}+1.80 \times 10^{-7} \exp \left(-2.114 \times 10^{-1} t\right)$ \\
\hline M5 & 28 days & $D(t)=8.69 \times 10^{-9}+0.47 \times 10^{-7} \exp \left(-5.552 \times 10^{-2} t\right)$ \\
\hline M6 & 28 days & $D(t)=1.24 \times 10^{-8}+0.63 \times 10^{-7} \exp \left(-7.482 \times 10^{-2} t\right)$ \\
\hline M6S1 & 28 days & $D(t)=4.02 \times 10^{-9}+1.34 \times 10^{-7} \exp \left(-7.552 \times 10^{-2} t\right)$ \\
\hline M6S2 & 28 days & $D(t)=2.85 \times 10^{-9}+2.14 \times 10^{-7} \exp \left(-8.882 \times 10^{-2} t\right)$ \\
\hline M7 & 28 days & $D(t)=1.70 \times 10^{-9}+1.30 \times 10^{-7} \exp \left(-8.261 \times 10^{-2} t\right)$ \\
\hline C6 & 7 days & $D(t)=9.71 \times 10^{-9}+1.74 \times 10^{-7} \exp \left(-6.407 \times 10^{-2} t\right)$ \\
\hline C6S1 & 7 days & $D(t)=3.72 \times 10^{-9}+1.54 \times 10^{-7} \exp \left(-6.509 \times 10^{-2} t\right)$ \\
\hline C6S2 & 7 days & $D(t)=1.10 \times 10^{-9}+1.18 \times 10^{-7} \exp \left(-6.455 \times 10^{-2} t\right)$ \\
\hline
\end{tabular}

*:unit of $t$ is day

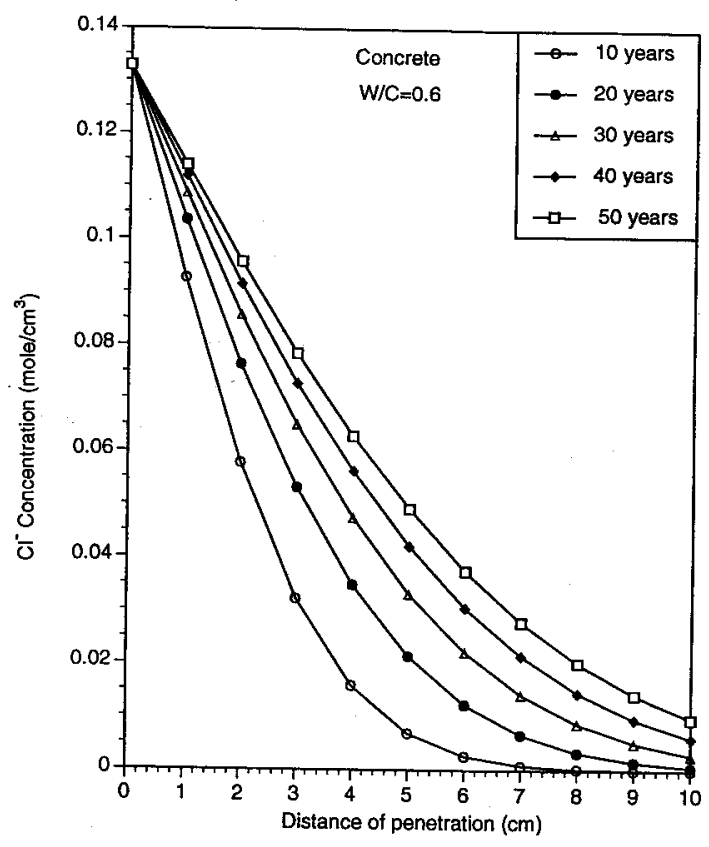

Fig. 8. Prediction of penetration depth vs. chloride ions' content diagram.

coarse aggregates. Best-fit curves can be found according to the selected mathematical model and the prediction of chloride penetration depth is possible.

\section{ACKNOWLEDGEMENT}

The authors wish to express sincere thanks to finacial support of this study by Taiwan Area NationalExpressway
Engineering Bureau (TANEEB).

\section{REFERENCES}

1. Funahashi, M., “ Predicting Corrosion-Free Service Life of a Concrete Structure in a Chloride Environment." ACI Materials Journal, Vol. 87, No. 6, pp. 581587, November - December, 1990.

2. Nagano, H. and Takafumi, N., "Application of Diffusion Theory to Chloride Penetration into Concrete Located in Splashing Zones." Transaction of Japan Concrete Institute, Vol. 7, pp. 157-164, 1985.

3. Tikalsky, P. J., et al, "Strength and Durability Consideration Affecting Mix Proportioning of Concrete Containing Fly Ash." ACI Materials Journal, November - December, pp. 505-511, 1986.

4. Maslehuddin, M. et al, "Effect of Sand Replacement on the Early-Age Strength Gain and Long-Term Corrosion Resisting Characteristics of Fly Ash Concrete." ACI Materials Journal, January - Feburary, pp. 58-62, 1989.

5. Page, C. L., Short, N. R. and Tarras, A. el., "Diffusion of Chloride Ions in Hardened Cement Pastes." Cement and Concrete Research, Vol. 11, No. 3, pp. 395-406, 1981.

6. Gjørv, O. E. and Vennesland, $\emptyset$, “ Diffusion of Chloride Ions from Seawater into Concrete." Cement and Concrete Research, Vol. 9, No. 2, pp. 229-238, 1979.

7. Clear, K. C. and Hay, R. E., " Time-to-Corrosion of Reinforcing Sted Slatos, Val. 1: Effect of Mix Derim. and Construction Parameters." Interim 
FHWA-RD-73-32, Fedral Highway Administration, Washington, D. C., April, pp. 103-105, 1973.

8. Page, C.L., Short, N.R. and Holden, W. R., "Influence of Different Cements on Chloride-Induced Corrosion of Reinforcing Steel." Cement and Concrete Research, Vol. 16, No. 1, pp. 79-86, 1986.

9. Subramanian, E. V. and Wheat, H.G., "Depassivation Time of Steel Reinforcement in a Chloride Enviroment - A One-Dimensional Solution." Corrosion Science,
Vol. 45, No. 1, pp. 43 - 48, 1989.

10. Mangat, P.S. and Gurusamy, K., "Chloride Diffusion in Steel Fiber Reinforced Marine Concrete." Cement and Concrete Research, Vol. 17, pp. 385-389, 1987.

11. Mangat, P. S. and Gurusamy, K., "Chloride Diffusion in Steel Fiber Reinforced Concrete Containing PFA." Cement and Concrete Research, Vol. 17, pp. 640-650, 1987. 